\title{
LAS «TROVADORAS» DE CRISTINA PERI ROSSI EN «PRIMER AMOR»
}

\author{
Estrella Díaz Fernández \\ Universitat de Barcelona
}

\section{RESUMEN}

«Primer amor», de Cristina Peri Rossi, apareció en 1996 en el volumen Madres e hijas, editado por Laura Freixas. Este libro de relatos breves aborda las relaciones maternofiliales, aunque Cristina Peri Rossi va más allá, pues su cuento no solo refleja su cariño y admiración hacia su progenitora, sino que se convierte en un texto de denuncia contra las leyes que prohibían el matrimonio entre dos mujeres. Uno de los elementos que emplea la autora hispano-uruguaya reiteradamente a lo largo de la narración es la remisión subversiva a las «trovadoras» provenzales, una pequeña élite de poetisas medievales enmarcadas en la corriente literaria del amor cortés que trastocaron el sujeto/objeto del discurso poético en la Romania. Su inclusión en el relato logra desestabilizar el discurso hegémonico.

PAlabras Clave: trovadoras provenzales, relaciones maternofiliales, cuentos escritos por mujeres, reivindicación matrimonio igualitario.

\section{CRISTINA PERI ROSSI'S «TROUBADOURS» \\ IN «PRIMER AMOR»}

\section{Abstract}

"Primer amor» (1996), by Cristina Peri Rossi, was included in the volume Madres e hijas, edited by Laura Freixas. This book of short stories deals with relationships between mothers and daughters. Peri Rossi not only reflects her affection and admiration for her mother, but turns the text into one of denunciation against the laws prohibiting marriage between two women. One of the elements that the Spanish-Uruguayan author uses repeatedly throughout the narrative is the subversive recall and reference to the female Provençal "troubadours", a small elite of medieval poetesses framed in the literary movement of courtly love who changed the subject/object of poetic discourse in the romance language countries. By including them in the story the Peri Rossi manages to destabilize the hegemonic discourse.

Keywords: Provençal troubadours, mother-daughter relationships, stories written by women, same sex marriage demand. 
El objetivo del presente trabajo ${ }^{1}$ es analizar las referencias al universo de las primeras poetas medievales en el cuento "Primer amor», de Cristina Peri Rossi, y reflexionar sobre sus significaciones estéticas e ideológicas. Este relato fue escrito expresamente para la antología Madres e hijas, editada para Anagrama por la escritora Laura Freixas en 1996, quien la elaboró tras constatar la carencia de obras literarias que tratasen las relaciones maternofiliales -en contraposición a las que se ocupaban de los vínculos entre padre-hijo, madre-hijo o padre-hija ${ }^{2}-$. Una de las características más relevantes de este volumen es que recoge exclusivamente cuentos de escritoras: se trata de una circunstancia que, como ella misma alegaba en su prólogo, podía ser objeto de crítica, al considerarse «sexista», aunque, a pesar de que la irrupción de las mujeres en las letras españolas haya sido notable desde la década de los años cuarenta del siglo Xx, está muy lejos de ser paritaria con la de los hombres. Los datos que aportaba la editora resultaban muy elocuentes, tanto en número de publicaciones como de representación en la Real Academia Española o en la nómina de los grandes premios institucionales; incluso es notable su ausencia en la historiografía de nuestra literatura, en la cual son ignoradas o rebajadas sistemáticamente ${ }^{3}$.

De este modo, a fin de abarcar un espectro generacional amplio, por este volumen transitan escritoras de muy diversas generaciones, empezando con Rosa Chacel (1898-1994) y acabando con Luisa Castro (1966-)4. Los enfoques y puntos de vista de los cuentos son dispares, pues no todos idealizan la relación; así, mientras que algunos retratan las difíciles intimidades maternofiliales -como los de Ana María Matute, Esther Tusquets, Soledad Puértolas o Almudena Grandes-, otros se revelan como un homenaje a la figura materna -los de Carmen Martín Gaite, Josefina Aldecoa, Clara Sánchez o Luisa Castro-. Entre estos últimos se encuentra el de Cristina Peri Rossi, aunque nuestra escritora vaya más allá, pues este relato no solo refleja el cariño y admiración hacia su progenitora, sino que se convierte en un texto feminista de denuncia contra las leyes que prohibían el matrimonio entre personas del mismo sexo, además de trazar una genealogía de mujeres escritoras a partir de la inclusión de las trovadoras medievales. En este sentido, Peri Rossi parece anticiparse a la argumentación que Laura Freixas introdujo en el prólogo de una antología posterior ${ }^{5}$, titulada Cuentos de amigas:

${ }_{1}$ Este trabajo forma parte del proyecto «Diversidad de género, masculinidad y cultura en España, Argentina y México» (FEM2015-69863-P MINECO-FEDER).

2 Resulta oportuno destacar que este relato no se ha incluido en la mayoría de recopilaciones de cuentos de nuestra autora, razón por la cual apenas ha sido estudiado.

${ }^{3}$ L. Freixas. Madres e hijas. Barcelona: Anagrama, 1996.

${ }^{4}$ La nómina completa la conforman, en orden de aparición y cronológico, Rosa Chacel, Carmen Laforet, Carmen Martín Gaite, Ana M. ${ }^{a}$ Matute, Josefina R. Aldecoa, Esther Tusquets, Cristina Peri Rossi, Ana María Moix, Soledad Puértolas, Clara Sánchez, Paloma Díaz-Mas, Mercedes Soriano, Almudena Grandes y Luisa Castro.

5 En esta segunda antología, también participaba Peri Rossi con el relato titulado «La semana más maravillosa de nuestras vidas», publicado en el volumen Desastres intimos (1994). 
Yo considero que existe una literatura femenina con características propias; pero no quiero decir con ello que todas las mujeres escriban igual, ni que sus obras sean radicalmente distintas de las de los varones. Lo que tienen en común es su punto de partida: la falta de una tradición de mujeres autoras, y el papel limitado, accesorio, más que objeto - de los deseos y fantasías masculinas- que de sujeto, que les ha otorgado la literatura escrita por hombres. Es comprensible que lo primero que hayan hecho, y sigan haciendo, las escritoras sea crear personajes de mujer más ricos y diversos, menos centrados en sus relaciones con el sexo opuesto, más sujetos de su propia historia y más implicados en la relación con otras mujeres, que los recibidos de la tradición ${ }^{6}$.

La trayectoria vital y literaria de nuestra escritora resulta, por esta razón también, de indudable interés: nacida en Montevideo en 1941, debió exiliarse de su país en 1972 a causa de la dictadura militar. Una vez en Barcelona, se le denegó la nacionalidad uruguaya y, puesto que durante la dictadura franquista no estaba contemplado el derecho de asilo, se vio forzada a trasladarse a París en 1974, a lo que ella llamó «su segundo exilio». Elena Poniatowska seńalaba que, sin duda, fueron años difíciles para Peri Rossi, pues en cuanto pudo regresó legalmente a Barcelona, ciudad en la que sigue residiendo ${ }^{7}$. Su carrera literaria ha sido y es valorada como una de las más originales de las letras hispanoamericanas de las últimas décadas. Publicó su primer libro en 1963 y obtuvo los premios más importantes de Uruguay, pero su obra fue prohibida, así como la mención de su nombre en los medios de comunicación, durante la dictadura militar que gobernó el país entre 1973 y 1985. Cabe destacar que es la única autora que suele vincularse al boom latinoamericano, fenómeno editorial de los años 60 y 70 que dio a conocer en España la obra de autores como Gabriel García Márquez, Julio Cortázar, Mario Vargas Llosa y Carlos Fuentes, entre otros. Según constata Jesús Gómez de Tejada ${ }^{8}$, en la introducción a un reciente volumen de estudios sobre su obra, Peri Rossi «se configura como una de las autoras más significativas del siglo xx y comienzos de la actual centuria en el ámbito hispánico». Esta importancia se revalida en su diversidad: "La calidad de su dilatada trayectoria como creadora en muy diversos registros (de la poesía lírica, el relato breve o la novela, al ensayo el artículo de prensa y la traducción) ha propiciado que sus obras hayan sido editadas en varias lenguas y países»" Pero, aunque haya cultivado todos estos géneros literarios, el registro poético es el más extenso,

${ }^{6}$ L. Freixas. Cuentos de amigas. Barcelona: Anagrama, 2009.

E. Poniatowska. «Presentación», en C. Peri Rossi. El pulso del mundo. Artículos periodísticos: 1978-2002, México: Universidad Autónoma de la Ciudad de México, 2005, pp. 13-22.

8 J. Gómez de Tejada. "Cristina Peri Rossi: voces para atisbar la eternidad», en J. Gómez DE Tejada (coord.). Erotismo, transgresión y exilio: las voces de Cristina Peri Rossi, Sevilla: Universidad de Sevilla, 2017, pp. 15-20.

9 R.M. MÉRIdA Jiménez. «Cristina Peri Rossi en Triunfo: género y sexualidad en la prensa de la Transición española». Cuadernos de investigación filológica, vol. 41 (2015), pp. 129-139. 
en el que destacan los volúmenes Evohé (1971), Lingüistica general (1979), Otra vez Eros (1994), Estados de exilio (2003), Playstation (2009) o Las replicantes (2016) ${ }^{10}$.

"Primer amor» ${ }^{11}$ se inicia con una sorprendente declaración: "La primera vez que me declaré a mi madre tenía tres años». A continuación, la voz narrativa rememora por qué quería casarse con ella y emplea el recurso de la comparación para contraponer la relación entre ambas y la que tenía su madre con su padre. Así, el lector descubre que el matrimonio había sido un fracaso, marcado por una relación tormentosa en la que abundaban los reproches y disputas con un marido que apenas estaba en casa: "Aparecer y desaparecer sin aviso era una forma de poder» ${ }^{12}$. La sorpresa que una afirmación como esta pueda provocar entre los lectores poco conocedores de la obra de nuestra autora bien puede ser mayúscula; no así entre los más avezados, pues, por ejemplo, Julia González Calderón ha destacado que «son numerosas las narraciones de Cristina Peri Rossi en que los nińos cumplen con un papel protagonista. La historia de estos niños son historias de rebeldía, de asalto contra las formas arcaicas, osificadas y tiránicas de poder $\aleph^{13}$. Por otra parte, nuestra autora ha reflexionado en diversas ocasiones en torno a su voluntad transgresora. Así, en un texto reciente, afirmaba que "siempre he querido escribir sobre los deseos reprimidos, apenas esbozados, sobre el conflicto entre el deseo y las normas sociales, sobre lo que soñamos y no podemos realizar porque la interdicción moral lo impide. Me parece el gran tema del arte, y excita mi imaginación $»^{14}$.

Según Ana Corbalán, en «Primer amor» se percibe «una desestabilización de la institución familiar patriarcal y una crítica ante este modelo tradicional. [...] Esta estructura patriarcal ha contribuido a reforzar la imposición del modelo falocéntrico como el icono representativo de lo que comúnmente se considera la familia normal. Mediante la presentación y denuncia de la disfuncionalidad de esta configuración familiar, Peri Rossi efectúa una llamada a la conciencia del lector $»^{15}$. En cambio, ambas, a juicio de la narradora, forman «una pareja perfecta ${ }^{16}$, pues aman la música clásica, los cuentos tradicionales, la poesía y la ciencia, comparten juegos, emociones, alegrías y temores; también saben negociar cuando surge algún conflicto, se aprecian y valoran y entre ellas hay amor, ternura, complicidad y felicidad: "Creo que se sintió halagada. El desgraciado matrimonio con mi padre la hacía sentirse muy desdichada, y necesitaba ser amada tiernamente, respetada, admirada; comprendió rossi.es/web/.

${ }_{10}$ Para una más completa nómina de su producción literaria, véase http://cristinaperi-

${ }^{11}$ C. Peri Rossi. «Primer amor», en L. Freixas (ed.), Madres e hijas, Barcelona: Anagrama, 1996, pp. 95-106.

12 Ibidem, p. 97.

13 J. González CAlderón. «Matar al padre: simbolismo y psicoanálisis en algunas narraciones de Cristina Peri Rossi», en J. Gómez de Tejada (coord.). Erotismo, transgresión y exilio..., pp. 173-190, p. 173.

${ }_{14}$ C. Peri Rossi. «Detente, instante, eres tan bello», ibidem, pp. 21-34, p. 33.

15 A. Corbalán. "Cuestionando la tradición patriarcal: la narrativa breve de Cristina Peri Rossi». Chasqui, vol. 37, núm. 2 (2008), pp. 3-14, p. 6.

16 C. Peri Rossi. «Primer amor», p. 97. 
que todos esos sentimientos (más un fuerte deseo de reparación) yo se los ofrecía de manera generosa y desprendida, como una trovadora medieval $\aleph^{17}$ (la cursiva es mía).

Esta descripción de los sentimientos de la nińa hacia su madre queda reforzada por la pregunta retórica "¿qué más podía pedirse a una pareja?», la cual aparece dos veces en el texto (pp. 97 y 99). La respuesta de la madre, cuando la niña tiene tres años, es que ella es aún muy pequeña para casarse:

Siempre le agradeceré a mi madre que me hubiera dado esa respuesta. No desestimó mi proposición, no me decepcionó, sino que estableció un motivo razonable y justo para posponer nuestra boda. Además, me estimuló a crecer [...] Mientras crecía (más lentamente de lo que yo hubiera deseado), renovaba, cada tanto, la promesa de matrimonio que le había hecho a mi madre. No sabía aún que los trovadores tenían una sola dama (lejana), pero intuía que debía ser así. Un amor eterno, delicado, fiel y cortés ${ }^{18}$.

Cuando la niña debe ir a la escuela (y en las disputas entre sus progenitores empieza a planear la palabra «divorcio»), vuelve a realizar su proposición, aunque en esta ocasión la explicación es distinta, puesto que es de tipo legal: «Del mismo modo que la ley exigía que yo fuera a la escuela, contra mi voluntad, la ley prohibía que una hija se casara con su madre ${ }^{19}$. A continuación, la madre explica cuál es el proceso para poder cambiar las leyes y cómo, tras la elaboración de un proyecto, este tiene que pasar por el Parlamento y el Senado antes de que llegue, si no ha sido desestimado antes, al Poder Ejecutivo, el cual también tiene derecho de veto y puede suspender eternamente la promulgación de la ley.

La interpretación que ofrece Ana Corbalán sería que «la autora presenta el deseo lésbico como razón de ser y como transgresión explícita ante la prohibición social del incesto»"; también señala que "la infracción que se observa en "Primer amor" del tabú tan arraigado en nuestra sociedad sobre el incesto constituye una de las más impactantes para el lector $\aleph^{21}$. A mi juicio, si bien el cuento logra desestabilizar el discurso hegemónico y reivindicar una relación lésbica, no se trataría en última instancia de un incesto, sino que estaría aludiendo claramente al «continuum lesbiano» propuesto por Adrienne $\mathrm{Rich}^{22}$, quien sostuvo que este concepto «incluye una gama de experiencia identificada con mujeres -en la vida de cada mujer y a lo largo de la historia-, no simplemente el hecho de que una mujer haya tenido o deseado conscientemente una experiencia sexual genital con otra mujer». Es decir, la poeta y ensayista estadounidense apostaba por una identificación entre mujeres, incluyendo a la criatura que mama del pecho de su madre, a la madre que experimenta sensaciones orgásmicas dando de mamar a su bebé o a la mujer de noventa

17 Ibidem, p. 98.

${ }^{18}$ Ibidem, pp. 98-99. La cursiva es mía.

19 Ibidem, p. 103.

20 A. Corbalán. "Cuestionando la tradición patriarcal..., p. 7.

${ }^{21}$ Ibidem, p. 8.

22 A. Rich. Sangre, pan y poesía. Prosa escogida 1979-1985. Barcelona: Icaria, 2001, p. 66. 
años que muere atendida por mujeres ${ }^{23}$. Esta propuesta se complementa con la relativa a la "existencia lesbiana» como una forma de rechazo al patriarcado, como un acto de resistencia ${ }^{24}$. En este sentido, Inmaculada Pertusa Seva ${ }^{25}$ ha podido iluminar la obra poética de nuestra autora de la mano de las teorías de Rich, Luce Irigaray y Hélène Cixous, o Elena Castro ${ }^{26}$ a partir de los estudios lésbicos y queer.

La remisión a las "trovadoras» tiene el objetivo de reivindicar una genealogía de mujeres poetas, pues las trobairitz en lengua occitana fueron una pequeña élite de creadoras medievales que trastocaron el sujeto/objeto del discurso poético en la Romania: ellas eran las amantes en lugar de las amadas. A pesar de la relevancia cuantitativa y cualitativa de los hombres «trovadores»-poetas-músicos del sur de Francia que escribieron entre los siglos XII y XIII, quienes crearon un código de comportamientos que fue bautizado como "amor cortés»-, cabe destacar que también hubo mujeres que vivieron y escribieron en el mismo periodo y que son los testimonios inaugurales escritos por mujeres en lengua románica ${ }^{27}$. Los temas que trataban estos poetas, y que son el ingrediente principal del «amor cortés», eran la humillación ante de la dama y el deseo como vía de perfeccionamiento material y espiritual, dirigido exclusivamente a mujeres casadas de un rango superior. Sus poesías, ambiguas y cautas, han favorecido interpretaciones diversas: algunos eruditos sugieren que se trata de un amor platónico, mientras que otros señalan que encubren adulterios y otros apuestan por una alegoría religiosa. En contraposición, la poesía de las trovadoras estaría orientada hacia el reconocimiento de la libertad del deseo, revelando sus propias experiencias y emociones más íntimas, separándose, así, de la lírica de los trovadores, según han investigado William D. Paden $^{28}$ e Isabel de Riquer ${ }^{29}$.

Otro elemento diferenciador reside en que la crítica considera que las mujeres escribían más por razones personales que profesionales, un hecho que favorecía que pudieran romper o ignorar la crítica más ritualizada de los varones. De este modo, observamos que las trovadoras no tenían interés alguno por ser veneradas ni adoradas, sino que intentan seducir al amado, o discutir con él para atraer su atención $^{30}$. Como vemos, la genealogía en la que se está enmarcando Cristina Peri Rossi al reivindicar y visibilizar la figura en «Primer amor" ya es subversiva de por sí, más aún si tenemos en cuenta que, como advierte Michela Pereira:

23 Ibidem, p. 68.

24 Ibidem, p. 66.

25 I. Pertusa Seva. La salida del armario. Lecturas desde la otra acera: Esther Tusquets, Carme Riera, Sylvia Molloy, Cristina Peri Rossi. Gijón: Libros del Pexe, pp. 105-157. pp. 99-114.

26 E. Castro. Poesía lesbiana queer. Cuerpos y sujetos inadecuados. Barcelona: Icaria,

27 La edición filológica más relevante para el estudio de las trovadoras en lengua occitana es la preparada por Angelica Rieger (1991).

28 W.D. Paden (ed.). The Voice of the Trobairitz. Perspectives on the Women Troubadours. Filadelfia: University of Pennsylvania, 1989.

29 I. DE RiQuer. "Las trobairitz», en I.M. Zavala (coord.), Breve historia feminista de la literatura española (en lengua catalana, gallega y vasca), Barcelona: Anthropos, 2000, pp. 27-39.

${ }_{30}$ M. Bogin. Les trobairitz. Poetes occitanes del segle XII. Barcelona: LaSal, 1983, pp. 74-75. 
En las poesías de las trobairitz destaca la capacidad de expresar el deseo femenino sin sublimarlo pero también sin reducirlo a exceso informe, capacidad que nace también o quizá sobre todo de su posibilidad de formar y afinar su pensamiento en un ámbito de relaciones entre mujeres [...] Las trobairitz vuelven así a hablarnos [...] y las descubrimos como antepasadas en la historia de una creatividad femenina capaz de no renegar de la libertad de su deseo y a la vez de enfrentarse con la alteridad que ponen en juego en todas sus relaciones ${ }^{31}$.

Por su parte, Magda Bogin ${ }^{32}$ señala que una de las figuras más «misteriosas» entre las trovadoras provenzales fue Bieiris de Romans, cuya canción «Na Maria, pretz e fina valors» ("Dońa María, dama de gran valor») está dirigida a otra mujer, aunque los estudiosos, como apunta esta investigadora, hayan recurrido a los argumentos más ingeniosos para evitar la conclusión de que se trata de una mujer que compone una canción amorosa dirigida a otra. No cabe duda que «de aceptar el lesbianismo de esta trobairitz nos encontraríamos con el único testimonio en lengua románica de todo el Medioevo en donde se expresaría en primera persona el deseo amoroso entre dos mujeres» ${ }^{33}$.

Además, Cristina Peri Rossi, por su implicación con el movimiento feminista en Barcelona tenía conocimiento del estudio de Bogin, publicado en 1983 en LaSal. Esta fue una editorial feminista fundada en 1978 por Mari Chordà, Mariló Fernández, Isabel Martínez e Isabel Monteagudo cuyo objetivo fue el de

... difundir escritos de mujeres que reflexionaban sobre el lenguaje, reconociendo su rol fundamental dentro de la estructura cultural patriarcal. [...] Asimismo se pretendía dar visibilidad a escritoras españolas del pasado, olvidadas, y a libros de mujeres y de teoría feminista, difundiendo puntos de vista diferentes, tanto europeos como latinoamericanos, que normalmente se quedaban fuera del circuito de distribución ${ }^{34}$.

La editorial nació como un proyecto posterior del local $\mathrm{LaSal}^{35}$; emplazado en el Raval de Barcelona, fue creado como un espacio de mujeres y para las mujeres y era un híbrido entre un bar y un espacio artístico, cultural y político donde «se

31 M. Pereira. "Introducción», en M. Martinengo. Las Trovadoras. Poetisas del amor cortés (Textos provenzales con traducción castellana), Madrid: Horas y Horas, 1996, pp. 5-11, p. 11.

32 M. Bogin. Les trobairitz..., p. 102.

33 R.M. MÉrida Jiménez. «Teorías presentes, amores medievales. En torno al estudio del homoerotismo en el Occidente medieval». Revista de poética medieval, vol. 4 (2000), pp. 51-98, p. 89.

${ }^{34}$ K. Almerini. «LaSal, bar-biblioteca feminista en Barcelona. Empoderamiento femenino y cultura visual». Boletín de Arte, vol. 35 (2014), pp. 83-100, p. 89.

35 Según recuerda M. Otero Vidal («Patchwork lèsbic», en M. Torras (ed.). Accions $i$ reinvencions. Cultures lèsbiques a la Catalunya del tombant de segle XX-XXI, Barcelona: UOC, 2011, pp. 41-46, p. 43), «una conseqüència de l'efervescència feminista dels anys setanta va ser la implantació a Barcelona de la Llibreria de les dones del carrer Lledó, núm. 10. No sé què se n’ha fet de les dones que la portaven i m’agradaria donar-los les gràcies, perquè certament per a mi era un goig anar-hi a trobar llibres ja seleccionats de lesbianisme». 
celebraban también debates sobre las cuestiones más sensibles para las feministas como la autogestión, las relaciones personales y los grupos, la maternidad, el lesbianismo, la doble militancia» ${ }^{36}$. Así, no es extraño que la editorial se ocupara en una de sus primeras publicaciones de las trovadoras, pues «en esta figura se podría quizá reconocer una síntesis cultural alternativa a la que confeccionó el pensamiento escolástico medieval, que tuvo entre sus fundamentos la exclusión material y simbólica de las mujeres y de lo femenino de la vida intelectual ${ }^{37}$.

Desde esta encrucijada, podemos considerar la subversión feminista que deriva de la inclusión de las trovadoras en lengua occitana en el cuento y cómo, a partir de ellas, la autora logra no solo desestabilizar el discurso hegemónico, sino también denunciar las leyes que prohibían -y siguen prohibiendo en tantos paísesel matrimonio entre dos mujeres. Es así, también, como comprendemos la reflexión de una escritora que tanto ha luchado contra las dictaduras, a favor del feminismo y de los derechos de las minorías sexuales:

Muchos años después, reflexionando sobre este episodio de mi vida, le agradecí mucho a mi madre que no me explicara entonces, cuando tenía tan pocos años, que no podíamos casarnos porque ambas éramos del mismo sexo. [...] me hizo crecer con la convicción de que, a los efectos del amor, el sexo de los que se aman no tiene ninguna importancia. Como no la tienen el color de la piel, la edad, la escala social o la geografía ${ }^{38}$.

En este sentido, por consiguiente, podría afirmarse que en «Primer amor» confluirían diversos vectores de indudable importancia en la trayectoria literaria de nuestra autora: un claro compromiso feminista que defiende la autonomía y el empoderamiento de las mujeres, la expresión del deseo lésbico, la representación alternativa de masculinidades y feminidades, la transgresión de temas y formas narrativos heredados de la tradición patriarcal o la vindicación de una genealogía secular de creadoras ${ }^{39}$.

Recibido: febrero de 2019. Aceptado: marzo de 2019

36 K. Almerini. «LaSal, bar-biblioteca feminista...».

37 M. Pereira. «Introducción», en M. Martinengo (ed.), Las Trovadoras..., p. 6.

38 C. Peri Rossi. «Primer amor», p. 105.

39 Se trata, además, de un cuento que se proyecta sobre obras posteriores, según ha estudiado M. Torras. «Trabajos de amor (re)vividos. Afectos y efectos en Los amores equivocados (2015)», en J. Gómez de Tejada (coord.), Erotismo, transgresión y exilio..., pp. 259-279, pp. 276-278. 


\section{BIBLIOGRAFÍA}

Almerini, Katia. «LaSal, bar-biblioteca feminista en Barcelona. Empoderamiento femenino y cultura visual». Boletín de Arte, vol. 35 (2014), pp. 83-100.

Bogin, Magda. Les trobairitz. Poetes occitanes del segle XII. Trad. de Montserrat Abelló. Barcelona: LaSal, 1983.

Castro, Elena. Poesía lesbiana queer. Cuerpos y sujetos inadecuados. Barcelona: Icaria, 2014.

Corbalán, Ana. "Cuestionando la tradición patriarcal: la narrativa breve de Cristina Peri Rossi». Chasqui, vol. 37, núm. 2 (2008), pp. 3-14.

Freixas, Laura (ed.). Madres e hijas. Barcelona: Anagrama, 1996.

Freixas, Laura (ed.). Cuentos de amigas. Barcelona: Anagrama, 2009.

Gómez de Tejada, Jesús. «Cristina Peri Rossi: voces para atisbar la eternidad», en Jesús Gómez de Tejada (coord.). Erotismo, transgresión y exilio: las voces de Cristina Peri Rossi, Sevilla: Universidad de Sevilla, 2017, pp. 15-20.

GonzÁlez Calderón, Julia. «Matar al padre: simbolismo y psicoanálisis en algunas narraciones de Cristina Peri Rossi», en Jesús Gómez de TeJada (coord.), Erotismo, transgresión y exilio: las voces de Cristina Peri Rossi, Sevilla: Universidad de Sevilla, 2017, pp. 173-190.

MÉrida Jiménez, Rafael M. «Teorías presentes, amores medievales. En torno al estudio del homoerotismo en el Occidente medieval». Revista de poética medieval, vol. 4 (2000), pp. 51-98.

Mérida Jiménez, Rafael M. «Cristina Peri Rossi en Triunfo: género y sexualidad en la prensa de la Transición española». Cuadernos de investigación filológica, vol. 41 (2015), pp. 129-139.

Otero Vidal, Mercè. «Patchwork lèsbic», en Meri Torras (ed.), Accions i reinvencions. Cultures lèsbiques a la Catalunya del tombant de segle XX-XXI, Barcelona: UOC, 2011, pp. 41-46.

Paden, William D. (ed.). The Voice of the Trobairitz. Perspectives on the Women Troubadours. Philadelphia: University of Pennsylvania, 1989.

Pereira, Michela. «Introducción», en Marirí Martinengo (ed.), Las Trovadoras. Poetisas del amor cortés. Textos provenzales con traducción castellana. Trad. poética de Ana Mañeru Méndez; trad. en prosa de María-Milagros Rivera Garretas, Madrid: Horas y Horas, 1997, pp. 5-11.

Peri Rossi, Cristina. «Primer amor», en Laura Freixas (ed.), Madres e hijas, Barcelona: Anagrama, 1996, pp. 95-106.

Peri Rossi, Cristina. «Detente, instante, eres tan bello», en Jesús Gómez de Tejada (coord.), Erotismo, transgresión y exilio: las voces de Cristina Peri Rossi, Sevilla: Universidad de Sevilla, 2017, pp. 21-34.

Pertusa Seva, Inmaculada. La salida del armario. Lecturas desde la otra acera: Esther Tusquets, Carme Riera, Sylvia Molloy, Cristina Peri Rossi. Gijón: Libros del Pexe, 2005.

Poniatowska, Elena. «Presentación», en Cristina Peri Rossi, El pulso del mundo. Artículos periodísticos: 1978-2002, México: Universidad Autónoma de la Ciudad de México, 2005, pp. 13-22.

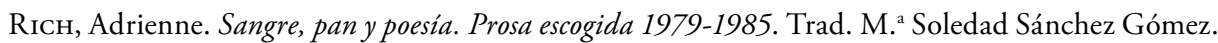
Barcelona: Icaria, 2001.

RIEger, Angelica. Trobairitz. Der Beitrag der Frau in der altokzitanischen höfischen Lyrik. Edition des Gesamtkorpus. Tubinga: Max Niemeyer, 1991. 
RiQuer, Isabel de. "Las trobairitz», en Iris M. ZAVALA (coord.). Breve historia feminista de la literatura española (en lengua catalana, gallega y vasca), Barcelona: Anthropos, 2000, pp. 27-39.

Torras, Meri (ed.). Accions i reinvencions. Cultures lèsbiques a la Catalunya del tombant de segle XX-XXI. Barcelona: UOC, 2011.

Torras, Meri. «Trabajos de amor (re)vividos. Afectos y efectos en Los amores equivocados (2015)», en Jesús Gómez de Tejada (coord.). Erotismo, transgresión y exilio: las voces de Cristina Peri Rossi, Sevilla: Universidad de Sevilla, 2017, pp. 259-279. 